\title{
Monodispersed mesoporous silica nanospheres based on pyridinium ionic liquids
}

\author{
Eleen Dayana Mohamed Isa ${ }^{1}$ Mohd Basyaruddin Abdul Rahman $\cdot$ Haslina Ahmad ${ }^{1}$
}

Published online: 13 January 2018

(c) The Author(s) 2018. This article is an open access publication

\begin{abstract}
In the past decades, ionic liquids (ILs) have garnered a lot of attention especially in the field of green chemistry due to their unique properties which help to solve the problems posed by organic solvents. Interestingly, their applications are not limited to that only as ILs have the potential to become alternative templates in the development of mesoporous silica nanoparticles (MSNs). This work reported the usage of a series of pyridinium ILs as template in the synthesis of monodispersed mesoporous silica nanosphere (MNSs) via two methods. Both syntheses utilize triethanolamine (TEA) as the base catalyst where in one method the TEA undergoes pre-treatment process while the other did not. Besides that, the effects of pyridinium ILs alkyl chain length were also investigated. MNSs generated via both methods exhibit spherical morphology and decreasing average particles size with increasing alkyl chain length of pyridinium ILs. The MNSs porosity were further analyzed through nitrogen sorption analysis where the surface area were in between 71.85 and $525.02 \mathrm{~m}^{2} \mathrm{~g}^{-1}$ and the pore volume was up to $1 \mathrm{~cm}^{3} \mathrm{~g}^{-1}$.
\end{abstract}

Keywords Mesoporous silica nanoparticles · Ionic liquids · Synthesis

\section{Introduction}

Since the discovery of ordered mesoporous silica in the 1990s, mesoporous silica nanoparticles (MSNs) have garnered a lot of attention. Mesoporous for MSNs is define through the pore diameter where it lies in between 2 and $50 \mathrm{~nm}$ while materials with pore diameter $<2 \mathrm{~nm}$ or $>$ $50 \mathrm{~nm}$ are classified as microporous or macroporous materials respectively [1]. The tremendous attentions on MSNs are due to its desirable properties such as high surface area, large pore volume and easy functionalization [2, 3]. Furthermore, this material can be tailored according to the type of applications and some of the common applications of this material are as catalyst, absorbent, in separation techniques and in the biomedical industry [1, 4-6]. However,

Electronic supplementary material The online version of this article (https://doi.org/10.1007/s10934-018-0556-9) contains supplementary material, which is available to authorized users.

Haslina Ahmad

haslina_ahmad@upm.edu.my

1 Department of Chemistry, Faculty of Science, Universiti Putra Malaysia, 43400 UPM Serdang, Selangor, Malaysia for biomedical applications, it is important that the MSNs generated are monodispersed with particles size $<100 \mathrm{~nm}$ as it is advantageous in cell endocytosis process [7].

MSNs can be synthesized through several approaches such as a modified Stöber method, fast-self assembly, soft and hard templating, dissolving-reconstruction and modified aerogels $[8,9]$. However, among all these syntheses, the modified Stöber method is most frequently utilized. Stöber method is one of the most famous approaches in synthesizing monodispersed silica particles and this method has four main components which are ammonia, water, ethanol and silica source. In order to obtain MSNs, modification was done by introducing template into the system [10]. For example, Haynes et al. utilizes this modified Stöber method in developing monodispersed MSNs by controlling the particles size with manipulation of the temperature, amount of TEOS and amount of ammonia [11-13]. Besides this method, Yano et al. successfully synthesized monodispersed MSNs by optimizing the concentration of reactant and the water/alcohol ratio [14-16]. However, the syntheses were conducted in large volume thus making the collection of product difficult. Bein et al. reported on the use of triethanolamine (TEA) as the base for the reaction as it would act as the catalyst and encapsulator in developing 
monodispersed MSNs [17]. In the recent years, Yamada et al. utilizes TEA in generating monodispersed MSNs while studying the effects of template amount, presence of alcohol, types of alcohols and alkyl chain length of the template on the synthesized MSNs [18-20]. All these researches used the common template which is cetyltrimethylammonium bromide or chloride $(\mathrm{CTAB} / \mathrm{CTACl})$. Zhang et al. discover a novel template, cetyltrimethylammonium tosylate (CTATos) to synthesize colloidal mesoporous silica [21]. Further researches were done on MSNs based on CTATos and a new type of MSNs known as dendritic MSNs was discovered [22]. Qiao et al. used mixture of CTATos and CTAB to generate dendritic MSNs. Besides that, they also study the effect of template composition, reaction temperature and time, and reagent ratio on the structure of MSNs produced [23]. Recently, Bein et al. found that by controlling the synthesis parameters, dendritic MSNs was generated using $\mathrm{CTACl}$ [24]. Dendritic MSNs is unique due to its open threedimensional (3D) dendritic structure with large pore channels and easily accessible compared to typical MSNs. It also garnered a lot attention in biomedical field due to the success of other organic dendrimer-drug conjugates entering the clinical test [25]. However, all the previous researches used the common type template which is quartenary ammonium salts and currently, there are fewer researches on alternative templates in developing monodispersed MSNs.

Ionic liquids (ILs) are salts made up of organic cations and organic or inorganic anions [26]. For a salt to be classified as ILs, the melting point of the compound must be below the boiling point of water. In the year 1914, the first IL discovered was ethylammonium nitrate $\left[\left(\mathrm{EtNH}_{3}\right)\left(\mathrm{NO}_{3}\right)\right]$ with melting point of $13-14{ }^{\circ} \mathrm{C}[26,27]$. Since then, ILs have been mostly used in the field of green chemistry as "green solvents" due to their intrinsic properties such as negligible vapor pressure, non-flammability, high thermal stability and great solvation capabilities [26-29]. Furthermore, desired properties of ILs can be achieved by tailoring its anions and cations. Although ILs are popular in the field of green chemistry, the capabilities of ILs as template in generating porous materials were unexplored.

Currently, several researches have reported the utilization of imidazolium based ILs in the development of mesoporous silica materials. Long chain imidazolium ILs are of particular interest due to its tendency to self-assemble which is preferred in developing ordered mesoporous materials [30]. A series of 1-alkyl-3-methylimidazolium chloride $\left(\mathrm{C}_{\mathrm{n}} \mathrm{MimCl}\right.$ where $n=10,14,16$ and 18 ) were used to prepare highly ordered lamellar silica via nanocasting technique and the developed silica exhibited microporosity [31]. Wang et al. used 1-hexadecyl-3-methylimidazolium chloride to develop ordered mesoporous silica, MCM-41 and MCM-48 via hydrothermal method [30]. Development of mesoporous silica is not limited to long chain imidazolium based ILs. Zhou et al. and Zhang et al. utilize 1-butyl-3-methylimidazolium tetrafluoroborate $\left(\mathrm{C}_{4} \mathrm{MimBF}_{4}\right)$ to synthesize mesoporous silica via a new mechanism, known as hydrogen bond-co$\pi-\pi$-stack $[1,32]$. Despite these many researches conducted on usage of ILs as template, only one research was able to use ILs to develop MSNs and in this research, it was found that MSNs morphology are dependent on the type of ILs used [33].

Here we present two synthesis methods that utilize ILs as templates in synthesizing monodispersed mesoporous silica nanospheres (MNSs). In both syntheses, TEA was used as the basic catalyst. Furthermore, the effects of alkyl chain length of the template on the MNSs morphology were also studied.

\section{Methodology}

\subsection{Materials}

Pyridine, 1-bromododecane, 1-bromotetradecane, 1-bromohexadecane, 1-bromooctadecane, ethanol, diethyl ether, acetonitrile, TEA, tetraethylorthosilicate (TEOS), hydrochloric acid $(\mathrm{HCl})$ was purchased from Chemolab Sdn Bhd. The chemicals were used without further purification.

\subsection{Characterization}

The Nuclear Magnetic Resonance (NMR) spectra for ${ }^{1} \mathrm{H}$ were recorded on JEOL EXC500 FT. Deuterated dimethyl sulfoxide (DMSO) was used as solvents for all ILs. Powder $\mathrm{X}$-ray diffractogram were collected on Brucker D8 Discover using $\mathrm{Cu} \mathrm{K} \alpha$ radiation over a $2 \theta$ range of $1-9^{\circ}$ at a scan rate of $1^{\circ} \mathrm{min}^{-1}$. Transmission electron micrographs (TEM) were recorded on Tecnai G2 F20 operating at $200 \mathrm{kV}$. Samples were dispersed in ethanol under ultrasonication for $20 \mathrm{~min}$. One droplet of suspension was applied to a 400-mesh carbon-coated copper grid and dried in air. Thermogravimetric (TG) analysis was conducted on TGA/SDTA 851 Mettler Toledo under dry air flow at a heating rate of $10{ }^{\circ} \mathrm{C} \mathrm{min}-1$. Brauner-Emmett-Teller (BET) surface area and average pore volume of the MNSs were measured by physisorption of $\mathrm{N}_{2}$ at $77 \mathrm{~K}$ over a Micromeritics TriStar II 3020. Before measurement, the samples were degassed at $200{ }^{\circ} \mathrm{C}$ for $6 \mathrm{~h}$ to remove moisture and adsorbed gas.

\subsection{Synthesis of pyridinium ILs}

The pyridinium ILs were prepared according to previously published researches and with some modifications [34, 35]. 1-dodecylpyridinium bromide $\left(\mathrm{C}_{12} \mathrm{PyBr}\right)$, 1-tetradecylpyridinium bromide $\left(\mathrm{C}_{14} \mathrm{PyBr}\right)$, 1-hexadecylpyridinium bromide $\left(\mathrm{C}_{16} \mathrm{PyBr}\right)$ and 1-octadecylpyridinium bromide $\left(\mathrm{C}_{18} \mathrm{PyBr}\right)$ 
were obtained by reacting pyridine $(33 \mathrm{mmol})$ with 1-bromododecane (40 mmol), 1-bromotetradecane (40 mmol), 1-bromohexadecane $(40 \mathrm{mmol})$ and 1-bromooctadecane $(40 \mathrm{mmol})$ respectively in ethanol $(10 \mathrm{~mL})$, at $110^{\circ} \mathrm{C}$ under reflux condition for $48 \mathrm{~h}$. The products obtained were purified by dissolving it in minimum amount of acetonitrile and precipitated using diethyl ether. The solids obtained were dried under desiccants to remove excess solvent. $\mathrm{C}_{12} \mathrm{PyBr} \mathrm{H}^{1}$ NMR (500 MHz, DMSO- $\left.d_{6}, \delta\right): 0.78-0.81(\mathrm{t}, J=6.85 \mathrm{~Hz}$, $\left.3 \mathrm{H} ; \mathrm{CH}_{3}\right), 1.20-1.23\left(\mathrm{~m}, 18 \mathrm{H} ;\left(\mathrm{CH}_{2}\right)_{9}\right), 1.85-1.88(\mathrm{~m}, 2 \mathrm{H}$; $\left.\mathrm{CH}_{2}\right), 4.57-4.60\left(\mathrm{t}, J=8.00 \mathrm{~Hz}, 2 \mathrm{H} ; \mathrm{CH}_{2}\right), 8.11-8.14(\mathrm{~m}$, 2H; Ar H), 8.56-8.59 (t, $J=8.00 \mathrm{~Hz}, 1 \mathrm{H} ; \mathrm{Ar} \mathrm{H}), 9.11-9.12$ (m, $2 \mathrm{H} ; \mathrm{Ar} \mathrm{H}) . \mathrm{C}_{14} \mathrm{PyBr} \mathrm{H}{ }^{1}$ NMR (500 MHz, DMSO- $d_{6}$,

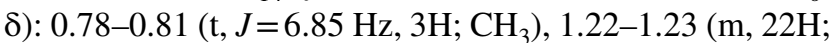
$\left.\left(\mathrm{CH}_{2}\right)_{11}\right), 1.85-1.88\left(\mathrm{~m}, 2 \mathrm{H} ; \mathrm{CH}_{2}\right), 4.57-4.60(\mathrm{t}, J=8.00 \mathrm{~Hz}$, $\left.2 \mathrm{H} ; \mathrm{CH}_{2}\right), 8.11-8.14(\mathrm{~m}, 2 \mathrm{H}$; Ar H) $8.56-8.59(\mathrm{t}$, $J=8.00 \mathrm{~Hz}, 1 \mathrm{H} ; \mathrm{Ar} \mathrm{H}), 9.11-9.12$ (m, 2H; Ar H). $\mathrm{C}_{16} \mathrm{PyBr}$ $\mathrm{H}^{1} \mathrm{NMR}\left(500 \mathrm{MHz}, \mathrm{DMSO}-d_{6}, \delta\right): 0.78-0.81(\mathrm{t}, J=6.86 \mathrm{~Hz}$, $\left.3 \mathrm{H} ; \mathrm{CH}_{3}\right), 1.18-1.22\left(\mathrm{~m}, 26 \mathrm{H} ;\left(\mathrm{CH}_{2}\right)_{13}\right), 1.85-1.88(\mathrm{~m}, 2 \mathrm{H}$; $\mathrm{CH}_{2}$ ), 4.57-4.60 (t, $\left.J=8.05 \mathrm{~Hz}, 2 \mathrm{H} ; \mathrm{CH}_{2}\right), 8.11-8.14$ (m, 2H; Ar H), 8.56-8.59 (m, 1H; Ar H), 9.11-9.12 (m, 2H; Ar H). $\mathrm{C}_{18} \mathrm{PyBr} \mathrm{H}^{1} \mathrm{NMR}\left(500 \mathrm{MHz}, \mathrm{DMSO}-d_{6}\right.$, $\delta$ ): 0.79-0.83 $\left(\mathrm{t}, J=6.86 \mathrm{~Hz}, 3 \mathrm{H} ; \mathrm{CH}_{3}\right), 1.18-1.23\left(\mathrm{~m}, 30 \mathrm{H} ;\left(\mathrm{CH}_{2}\right)_{15}\right)$, 1.85-1.88 (m, 2H; $\left.\mathrm{CH}_{2}\right), 4.54-4.58(\mathrm{t}, J=8.05 \mathrm{~Hz}, 2 \mathrm{H}$; $\left.\mathrm{CH}_{2}\right), 8.11-8.14(\mathrm{~m}, 2 \mathrm{H} ; \mathrm{Ar} \mathrm{H}), 8.55-8.59(\mathrm{~m}, 1 \mathrm{H} ; \mathrm{Ar} \mathrm{H})$, 9.06-9.07 (m, 2H; Ar H).

\subsection{MNSs synthesis}

\subsubsection{MNSs synthesis procedure a}

In this method, TEA and TEOS undergo a pre-treatment process and MNSs synthesis procedure A was modified from published resources [3, 36]. ILs $(0.5 \mathrm{~g})$ was dissolve in deionized water $(20 \mathrm{~mL})$ and this mixture was stirred at $90{ }^{\circ} \mathrm{C}$ for $1 \mathrm{~h}$. This mixture was labeled as Solution A (SA). In a small vial, TEA (0.06 g) and TEOS (1.5 mL) was mixed and heated. It was labeled as Solution B (SB). SB was added dropwise to SA and the mixture was then further stirred at $90{ }^{\circ} \mathrm{C}$ for another hour. After cooling to room temperature, the product was collected via centrifugation at 12,000 rotation per minute (rpm) for $30 \mathrm{~min}$. The product was washed with water and ethanol once respectively. To remove the template, the solid was dispersed in ethanol $(60 \mathrm{~mL})$ via sonication, followed by the addition of concentrated $\mathrm{HCl}(3 \mathrm{~mL})$. The mixture was then refluxed overnight. The template-removed product was collected via centrifugation and the solid obtain was rinsed with ethanol twice. The solid was dried in the oven at $50{ }^{\circ} \mathrm{C}$ for at least $12 \mathrm{~h}$. The products were named as MACn where $\mathrm{n}=12,14$, 16 and 18 which represented $\mathrm{C}_{12} \mathrm{PyBr}, \mathrm{C}_{14} \mathrm{PyBr}, \mathrm{C}_{16} \mathrm{PyBr}$ and $\mathrm{C}_{18} \mathrm{PyBr}$ respectively.

\subsubsection{MNSs synthesis procedure B}

In this method that was adapted and modified from Lv et al., there was no pre-treatment process for any reactants [3]. In $100 \mathrm{~mL}$ round bottom flask, ILs $(0.5 \mathrm{~g})$, deionized water $(20 \mathrm{~mL})$ and TEA $(0.06 \mathrm{~g})$ was added and the mixture was stirred for $1 \mathrm{~h}$ at $90{ }^{\circ} \mathrm{C}$. TEOS $(1.5 \mathrm{~mL})$ was added dropwise to the mixture and it was stirred for another hour at $90{ }^{\circ} \mathrm{C}$. After cooling to room temperature, the product was collected via centrifugation at $12,000 \mathrm{rpm}$ for $30 \mathrm{~min}$. The product was washed once with water followed by ethanol. To remove the template, the solid was dispersed in ethanol $(60 \mathrm{~mL})$ via sonication followed by the addition of concentrated $\mathrm{HCl}(3 \mathrm{~mL})$. The mixture was then refluxed overnight. The template-removed product was collected via centrifugation and the solid obtain was rinsed with ethanol twice. The solid was dried in the oven at $50{ }^{\circ} \mathrm{C}$ for at least $12 \mathrm{~h}$. The products were named as $\mathrm{MBCn}$ where $\mathrm{n}=12,14,16$ and 18 which represented $\mathrm{C}_{12} \mathrm{PyBr}, \mathrm{C}_{14} \mathrm{PyBr}, \mathrm{C}_{16} \mathrm{PyBr}$ and $\mathrm{C}_{18} \mathrm{PyBr}$ respectively.

\section{Results and discussion}

In this research, MNSs were synthesized using series of pyridinium ILs under basic condition via two methods. Comparatively to the other most common methods of MSNs synthesis, both of these methods utilize TEA instead of sodium hydroxide or ammonia. The usage of TEA as the base in this reaction is crucial in obtaining well dispersed particles [36]. The difference between these two methods is the utilization of TEA in the synthesis. In procedure A, the TEA and TEOS were premixed and preheated before adding it to the template mixture while in procedure $\mathrm{B}$, the TEA, template and water were mixed, heated and stirred together before the addition of room temperature TEOS. Other than comparing these two methods, the effects of alkyl chain length of pyridinium ILs via both methods were also investigated.

Before proceeding to the synthesis of MNSs, a series of pyridinium ILs were synthesized through established method as reported by Marek et al. [35]. In this reaction, ethanol was introduced in the mother solution to reduce the overall viscosity of the solution during the synthesis process. The target pyridinium ILs were formed through alkylation reaction between pyridine and bromoalkane with different alkyl chain lengths.

In both the procedures, MNSs were prepared under condensation reaction with TEA. TEA serves an important role in ensuring that the synthesized MNSs are well-dispersed due to its surface capping ligand property [3]. Besides that, it also acts as the basic catalyst for the reaction as well as a complexing agent with silicate species [37]. After obtaining 
the MNSs the series of pyridinium ILs (templates) were removed. This was observed via FTIR analysis. From the spectrum (Fig. 1), the disappearance of $\mathrm{sp}^{2} \mathrm{CH}$ stretching vibration around $3388 \mathrm{~cm}^{-1}, \mathrm{sp}^{3} \mathrm{CH}$ stretching vibration around 2852 and $2914 \mathrm{~cm}^{-1}$ and ring stretching vibration at 1481 and $1635 \mathrm{~cm}^{-1}$ which represent the ILs indicate that the template has been successfully removed. The appearance of new peak at $1064 \mathrm{~cm}^{-1}$ is the $\mathrm{SiO}$ bond which represents the formation of silica.

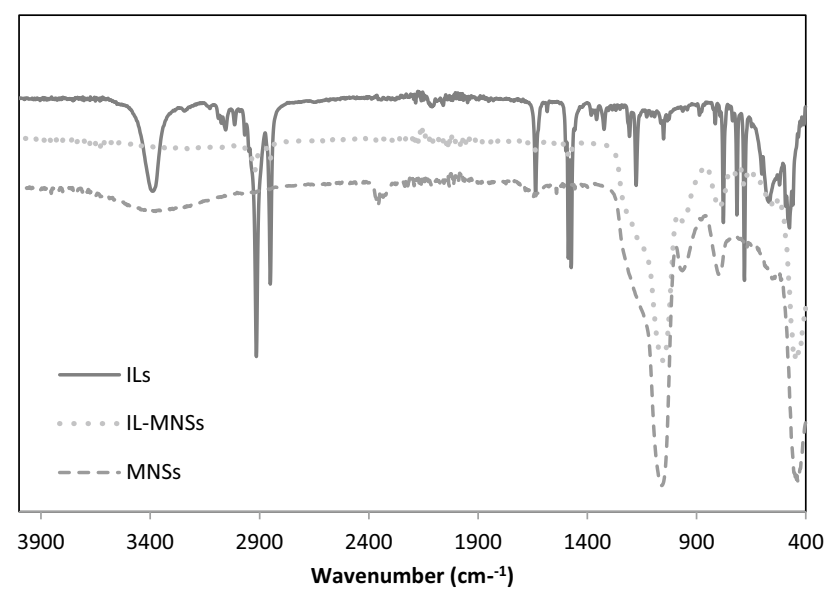

Fig. 1 FTIR spectrum of IL, IL-MNSs and MNSs alone
The synthesized MNSs were collected and analyze via small angle XRD (SAXRD). In a typical MCM-41 materials' SAXRD, there are three sharp peaks present at $2 \theta$ of 2.17, 3.74 and 4.35 [38]. However in both procedures, identical SAXRD patterns were obtained where the MNSs generated do not exhibit any peak which is identical to another reported work [1]. It can be concluded that the synthesized materials are amorphous with no specific pore ordering (Fig. S1) [1, 39].

In procedure $\mathrm{A}$, the MNSs were prepared by reacting two solutions with the same temperature where the templates and water solution were mixed with the TEA and TEOS solution. The TEM images (Fig. 2) reveals that all MACn materials exhibit spherical morphology in various sizes. Furthermore, in the TEM images, the pores show wormlike shape with no specific pore orientation. The mean diameters which were calculated from approximately 50 particles show decreasing order trend from MAC12, MAC14, MAC16 and MAC18 with the value of $157.23,62.97,57.66$ and $49.44 \mathrm{~nm}$ respectively (Table 1). Interestingly, the particles sizes are dependent on the alkyl chain length of pyridinium ILs. MAC12 exhibit the largest mean particle size of $157.23 \mathrm{~nm}$ while MAC18 has the lowest mean particle size of $49.44 \mathrm{~nm}$ which is more than half of the value given by MAC12. To confirm the presence of template within the MNSs, TG analysis on all MACn before the templates removal process were carried
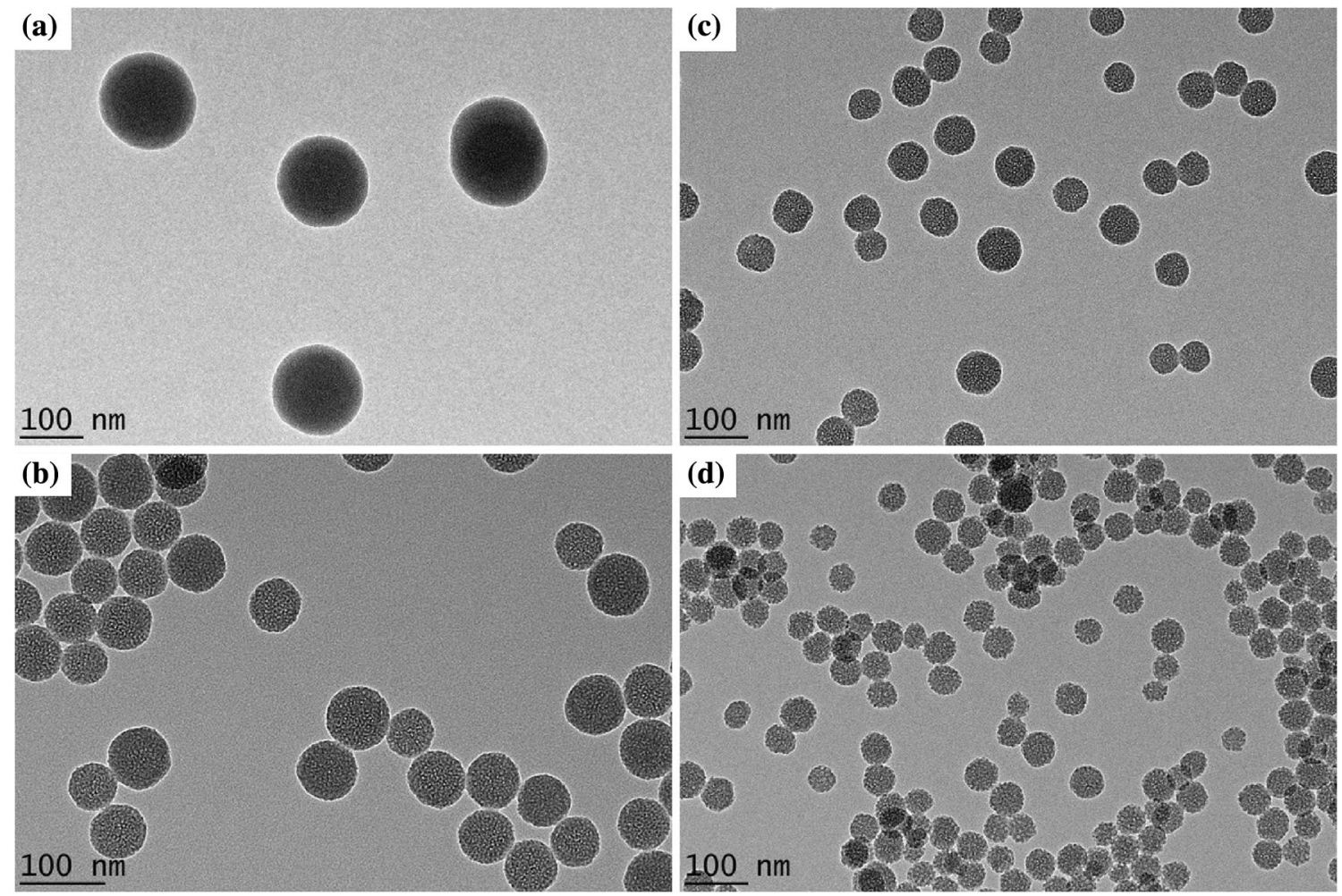

Fig. 2 TEM images of MACn. a MAC12, b MAC14, c MAC16 and d MAC18 
Table 1 Physicochemical properties of MACn

\begin{tabular}{lccl}
\hline MNSs & Mean particles size $(\mathrm{nm})$ & $\begin{array}{l}\text { BET surface } \\
\text { area }\left(\mathrm{m}^{2} \mathrm{~g}^{-1}\right)\end{array}$ & $\begin{array}{l}\text { Pore volume } \\
\left(\mathrm{cm}^{3} \mathrm{~g}^{-1}\right)\end{array}$ \\
\hline MAC12 & $157.23 \pm 11.3$ & 78.17 & 0.1998 \\
MAC14 & $62.97 \pm 5.09$ & 242.28 & 0.4543 \\
MAC16 & $57.66 \pm 4.67$ & 424.14 & 0.5951 \\
MAC18 & $49.44 \pm 4.73$ & 439.85 & 0.7141 \\
\hline
\end{tabular}

out. TG curves (Fig. S2) shows significant weight loss occurred between 250 and $500{ }^{\circ} \mathrm{C}$ which due the removal pyridinium ILs templates $[19,40]$.

The porosity of the synthesized MNSs was further examined by $\mathrm{N}_{2}$ adsorption-desorption and all MNSs sample exhibit type IV isotherm which is the norm for mesoporous materials (Fig. S4). Sharp intake at the relatively high pressure are due to the inter-particle spaces [41]. From the nitrogen sorption analysis, BET surface areas were obtained for MAC12, MAC14, MAC16 and MAC18 where surface area of $78.17,242.28,424.14$ and $439.85 \mathrm{~cm}^{3} \mathrm{~g}^{-1}$ were observed respectively (Table 1). The surface area exhibit an increasing trend with increasing alkyl chain length where an exponential increase of surface area was observed between MAC12 and MAC14 and that the surface area of MAC16 almost doubles the surface area of MAC14. Besides that, pore volumes of the materials were also obtained from this analysis and the same general trend as the surface area was observed.

Procedure B was adapted and modified from Lin et al. by replacing the common template $\mathrm{CTAB}$ with the series of pyridinium ILs prepared [3]. MNSs were synthesized by the addition of room temperature TEOS into the mother solution containing the templates, water and TEA. The properties of the MNSs were further examined via TEM analysis and it was found that $\mathrm{MBCn}$ show spherical morphology and wormlike pores shape (Fig. 3). The mean particle sizes calculated from about 50 particles were 150.50, 65.38, 56.67 and $45.59 \mathrm{~nm}$ for MBC12, MBC14, MBC16 and MBC18 respectively (Table 2). It was observed that the average particles size of MBC18 is more than half of MBC12 and drastic particles size decrease occurred between $\mathrm{MBC} 12$ and MBC14. The MBCn average particles size also exhibited decreasing trend as the $\mathrm{n}$ increases.

The sample MBCn were also analyzed via nitrogen sorption analysis and similar results to MACn were obtained. The materials exhibit typical mesoporous materials isotherm which is Type IV isotherm (Fig. S5). The surface area of the materials were determined via BET analysis whereby MBC12, MBC14, MBC16 and MBC18 have the surface area of $71.85,281.55,514.92$ and $525.02 \mathrm{~m}^{2} \mathrm{~g}^{-1}$ respectively (Table 2). From the data, it can be concluded that the surface area increases with the alkyl chain length and similar
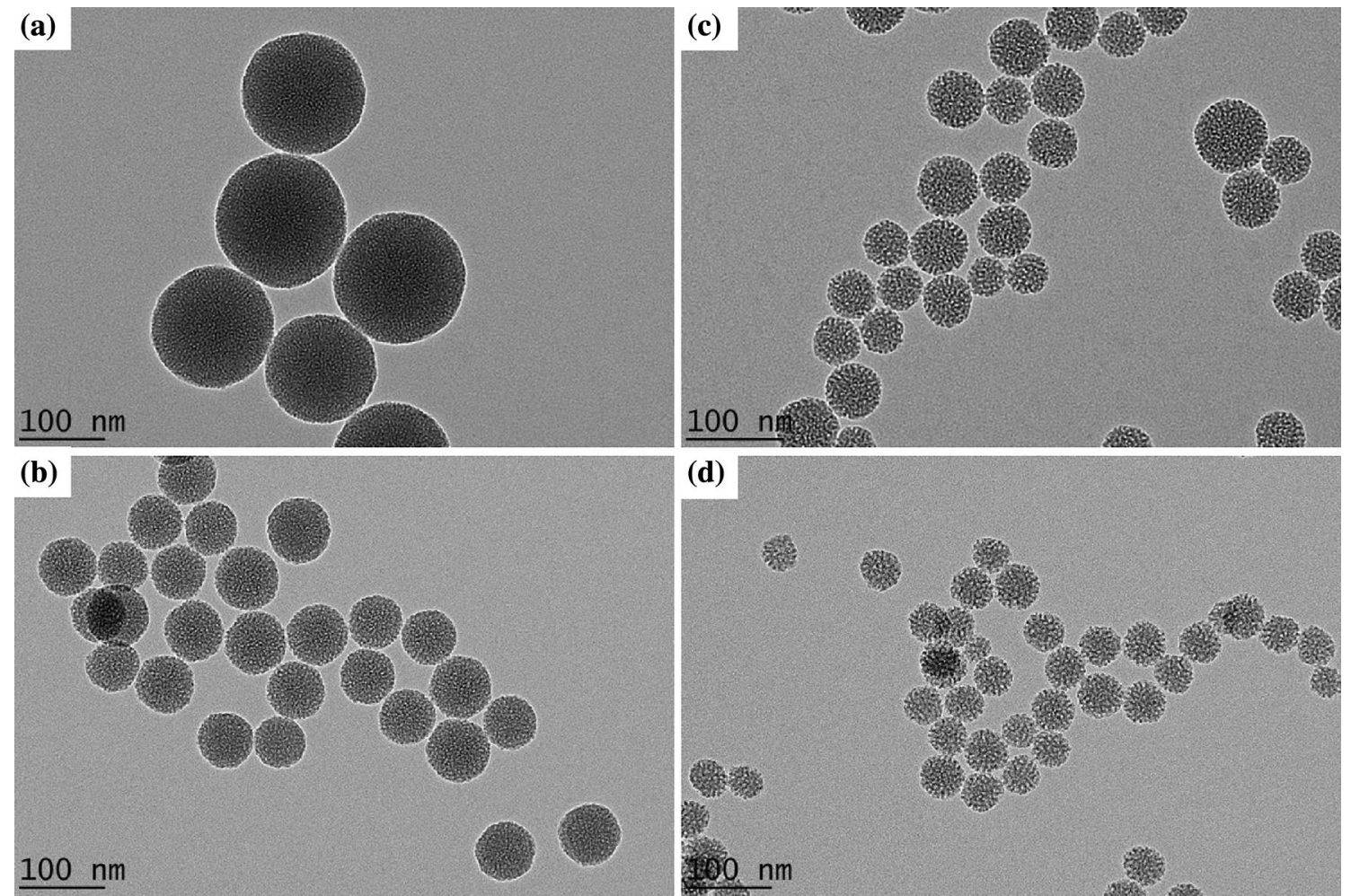

Fig. 3 TEM images of MBCn. a MBC12, b MBC14, c MBC16 and d MBC18 
Table 2 Physicochemical properties of MBCn

\begin{tabular}{lccl}
\hline MNSs & Mean particles size $(\mathrm{nm})$ & $\begin{array}{l}\text { BET surface } \\
\text { area }\left(\mathrm{m}^{2} \mathrm{~g}^{-1}\right)\end{array}$ & $\begin{array}{l}\text { Pore volume } \\
\left(\mathrm{cm}^{3} \mathrm{~g}^{-1}\right)\end{array}$ \\
\hline MBC12 & $150.20 \pm 10.70$ & 71.85 & 0.2185 \\
MBC14 & $65.38 \pm 5.77$ & 281.55 & 0.5804 \\
MBC16 & $56.67 \pm 5.98$ & 514.92 & 0.7767 \\
MBC18 & $45.59 \pm 4.21$ & 525.02 & 1.1163 \\
\hline
\end{tabular}

trend was observed from the pore volume data. Similarly to MACn, TG analysis on all MBCn before the templates removal was carried out to determine the presence of template. Significant weight loss occurred between 250 and $500{ }^{\circ} \mathrm{C}$ and this is due to removal of pyridinium ILs templates (Fig. S3) [19, 40].

To understand the formation mechanism of MNSs, one must first know the Classic Nucleation Theory (CNT). In CNT, there are three main stages which are the supersaturation of the monomers, nucleation and finally particles growth. Formation of MNSs follows the basic principle in CNT but in a slightly different way. From CNT, nucleation occurs when the supersaturation of monomer is achieved but for MNSs, the point of nucleation is from the micelle of the templates [3]. In other words, for the production of MNSs, the concentration of the templates must be more that the CMC value for the formation of micelles. In this reaction, we proposed that the MNSs were formed via chargedmechanism where the charge matching occur between the cationic template $\left(\mathrm{S}^{+}\right)$and silicate oligomers $\left(\mathrm{I}^{-}\right)$to form the $\mathrm{S}^{+} \mathrm{I}^{-}$assembly [2]. The formation of MNSs began with the production of cationic micelle followed by the interaction with negatively charged silicate species formed through hydrolysis of TEOS resulting in silica-template micelle composite. Constructions of MNSs began with silica-template micelle composite as building units and their condensation lead to the formation of nanoparticles [3]. Presence of TEA helps in monodispersity of MNSs by capping the surface of silica-template micelle which limits the particles growth. It also helps in the formation of more nuclei leading to smaller particles size [3, 17]. To investigate the capping agent (TEA) on synthesized MNSs, the samples were analyzed by FTIR analysis. From Fig. S6, the wide base between peaks at 3381 and $2913 \mathrm{~cm}^{-1}$ is due to hydroxyl group of TEA. The weak peak at $3065 \mathrm{~cm}^{-1}$ corresponds to the aliphatic chain of TEA. The peak representing in plane and out of plane bending of $\mathrm{C}-\mathrm{H}$ in TEA present around $1000 \mathrm{~cm}^{-1}$. However, the peak is covered by large and broad peak of $\mathrm{SiO}$ bond due to MNSs [42]. The peaks which indicate presence of TEA are weak due to low concentration of TEA used and the peak representing TEA overlap with the template's peak.

Figure 4 shows the comparison of mean particle size of MNSs with two different methods and various alkyl chain

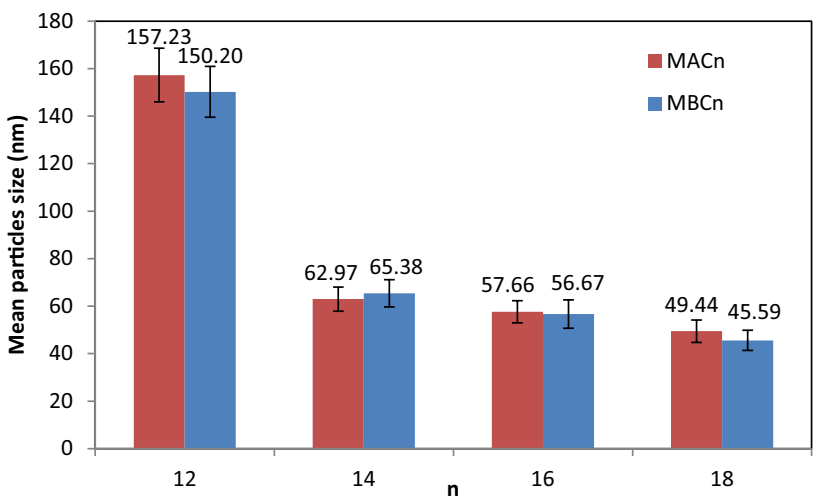

Fig. 4 Comparison of mean particles size between MACn and MBCn

length of template. Between the two methods, there were not many differences between the particles size. However in terms of dispersity, it was found that the MACn showed lower particles size's dispersity compared to MBCn. In procedure A, TEOS and TEA were pre-heated which resulted to formation of silatrane complex. This complex undergoes slower hydrolysis rate in aqueous medium hence the particles growth rate were more controlled which lead to lower particles size's dispersity. This observation was consistent with previous reported research [36]. Besides that, the general trend of decreasing particles size as alkyl chain length increases was demonstrated. One of the reasons for this observation is due to the critical micelle concentration (CMC) of the template. Template with longer alkyl chain length will have a lower CMC value and hence more nuclei will be observed in the solution state. This leads to a smaller particles size as the nucleation dominates the reaction [20, 41, 43].

The pores of the MNSs were analyzed using nitrogen sorption analysis and from this analysis, BET surface area and pore volume of the particles were obtained. For both methods, as the alkyl chain length increases, the surface area increases and the same trends were observed for the pore volume. Larger pore volume value leads to larger surface area which is consistent in both procedures. Furthermore it was observed in both procedures that there was exponential increase of surface area between $n=12$ and $n=14$ and the surface area reach a plateau state when $n=16$ and $n=18$. However, MNSs generated from procedure B show slightly higher surface area and pore volume compared to procedure A (Figs. 5, 6).

In procedure B, TEA was heated together in template aqueous solution and room temperature TEOS was added after an hour. Presence of TEA in the template solution increased the nuclei formation and was mentioned previously, nucleation point of MNSs is the template micelle. Addition of TEOS will react with the cationic micelle and form silica-template micelle composite which is the building 


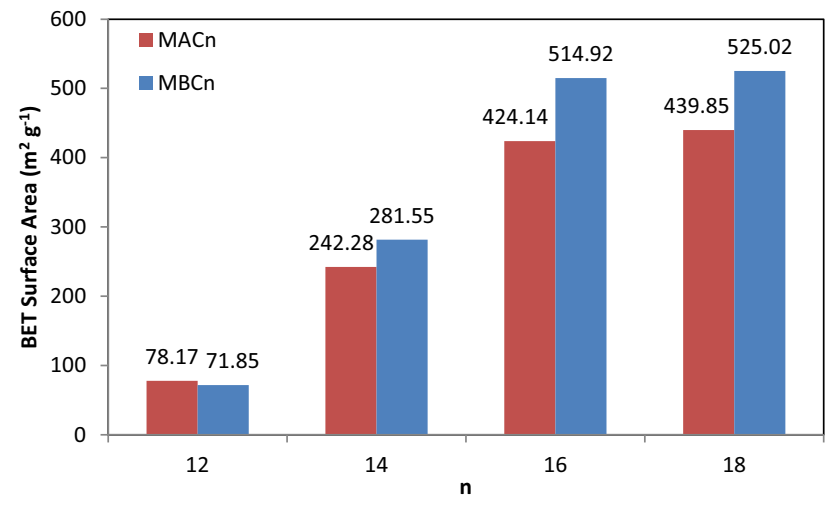

Fig. 5 Comparison of BET surface area between MACn and MBCn

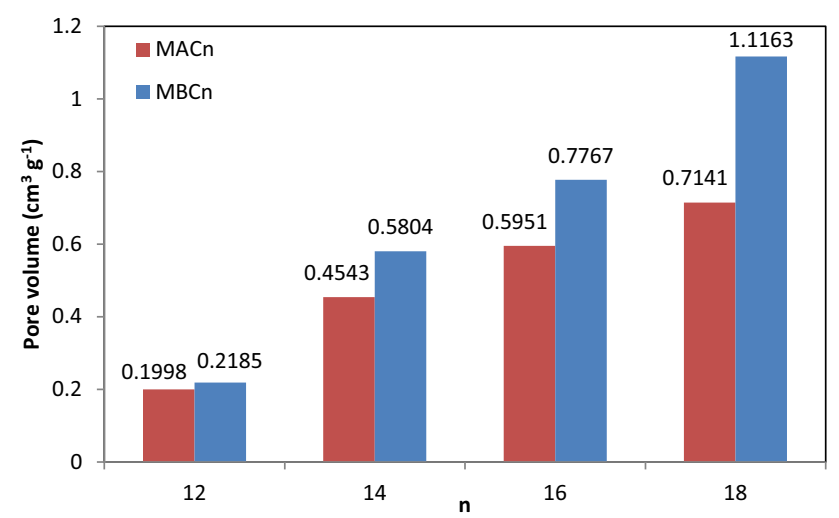

Fig. 6 Comparison of pore volume between MACn and MBCn

block of MSNs [3]. Higher concentration of these composite lead to more pores formation in the MSNs, hence giving rise to higher surface area and pore volumes values which are in agreement with the results obtained.

\section{Conclusion}

Monodispersed MNSs have been successfully synthesized using a series of pyridinium ILs via two methods. The particles sizes of the MNSs are affected by the alkyl chain length of the templates whereby the longer the alkyl chain length the smaller the particles size. In both methods, MNSs exhibited spherical morphology with wormlike pores shape. Based on the nitrogen sorption analysis, the BET surface area of MNSs generated from procedure A range from 78.17 to $439.85 \mathrm{~m}^{2} \mathrm{~g}^{-1}$ while from procedure $\mathrm{B}$, it is from 71.85 to $525.02 \mathrm{~m}^{2} \mathrm{~g}^{-1}$. This indicates that by removing the pretreatment process of TEA and TEOS, significant increase of surface area were obtained for the longer alkyl chain length template. The MNSs synthesized have potential to be utilized in catalysis, drug delivery, cell imaging and multifunctional materials due to its favorable properties.

Acknowledgements The authors gratefully acknowledge Universiti Putra Malaysia (GP-IPS/2016/9472600 and DT0063) and NanoMITe Health, Wellness and Medical research cluster (5526306) for supporting this work.

Open Access This article is distributed under the terms of the Creative Commons Attribution 4.0 International License (http://creativecommons.org/licenses/by/4.0/), which permits unrestricted use, distribution, and reproduction in any medium, provided you give appropriate credit to the original author(s) and the source, provide a link to the Creative Commons license, and indicate if changes were made.

\section{References}

1. J. Zhang, Y. Ma, F. Shi, L. Liu, Y. Deng, Microporous Mesoporous Mater. 119, 97-103 (2009)

2. Z. Li, L. Yu, L. Zheng, N. Li, S. Han, G. Li, J. Dispers. Sci. Technol. 29, 1029-1034 (2008)

3. X. Lv, L. Zhang, F. Xing, H. Lin, Microporous Mesoporous Mater. 225, 238-244 (2016)

4. Y.-D. Chiang, H.-Y. Lian, S.-Y. Leo, S.-G. Wang, Y. Yamauchi, K.C.W. Wu, J. Phys. Chem. C 115, 13158-13165 (2011)

5. L.L. Silva, I.P. Alkimim, P.A.S. Vasquez, D. Cardoso, Catal. Today 289, 2-13 (2017)

6. C. Argyo, V. Weiss, C. Bräuchle, T. Bein, Chem. Mater. 26, 435451 (2014)

7. M. Yu, L. Zhou, J. Zhang, P. Yuan, P. Thorn, W. Gu, C. Yu, J. Colloid Interface Sci. 376, 67-75 (2012)

8. S.-H. Wu, C.-Y. Mou, H.-P. Lin, Chem. Soc. Rev. 42, 3862 (2013)

9. V. Valtchev, L. Tosheva, Chem. Rev. 113, 6734-6760 (2013)

10. G. Chen, Z. Teng, X. Su, Y. Liu, G. Lu, J. Biomed. Nanotechnol. 11, 722-729 (2015)

11. Y.-S. Lin, C.L. Haynes, J. Am. Chem. Soc. 132, 4834-4842 (2010)

12. Y.-S. Lin, N. Abadeer, C.L. Haynes, Chem. Commun. 47, 532$534(2011)$

13. Y.S. Lin, N. Abadeer, K.R. Hurley, C.L. Haynes, J. Am. Chem. Soc. 133, 20444-20457 (2011)

14. Q. Chen, L. Han, C. Gao, S. Che, Microporous Mesoporous Mater. 128, 203-212 (2010)

15. K. Yano, T. Nishi, Microporous Mesoporous Mater. 158, 257-263 (2012)

16. K. Yano, M.B. Katz, X. Pan, N. Tatsuda, J. Colloid Interface Sci. 418, 61-65 (2014)

17. J. Kobler, K. Möller, T. Bein, ACS Nano 2, 791-799 (2008)

18. H. Yamada, C. Urata, Y. Aoyama, S. Osada, Y. Yamauchi, K. Kuroda, Chem. Mater. 24, 1462-1471 (2012)

19. H. Yamada, C. Urata, H. Ujiie, Y. Yamauchi, K. Kuroda, Nanoscale 5, 6145-6153 (2013)

20. H. Yamada, C. Urata, S. Higashitamori, Y. Aoyama, Y. Yamauchi, K. Kuroda, ACS Appl. Mater. Interfaces 6, 3491-3500 (2014)

21. K. Zhang, Y. Zhang, Q.W. Hou, E.H. Yuan, J.G. Jiang, B. Albela, M.Y. He, L. Bonneviot, Microporous Mesoporous Mater. 143, 401-405 (2011)

22. K. Zhang, L.-L. Xu, J.-G. Jiang, N. Calin, K.-F. Lam, S.-J. Zhang, H.-H. Wu, G.-D. Wu, B. Albela, L. Bonneviot, P. Wu, J. Am. Chem. Soc. 135, 2427-2430 (2013)

23. L. Xiong, X. Du, B. Shi, J. Bi, F. Kleitz, S.Z. Qiao, J. Mater. Chem. B 3, 1712-1721 (2015) 
24. K. Möller, T. Bein, Chem. Mater. 29, 371-388 (2017)

25. X. Du, S. Zhang, S.Z. Qiao, Small 11, 392-413 (2015)

26. M. Petkovic, K.R. Seddon, L.P.N. Rebelo, C.S. Pereira, Chem. Soc. Rev. 40, 1383-1403 (2011)

27. T. Welton, Chem. Rev. 99, 2071-2084 (1999)

28. M. Yu, S.M. Li, X.Y. Li, B.J. Zhang, J.J. Wang, Ecotoxicol. Environ. Saf. 71, 903-908 (2008)

29. J.G. Huddleston, A.E. Visser, W.M. Reichert, H.D. Willauer, G.A. Broker, R.D. Rogers, Green Chem. 3, 156-164 (2001)

30. T. Wang, H. Kaper, M. Antonietti, B. Smarsly, Langmuir 23, 1489-1495 (2007)

31. Y. Zhou, M. Antonietti, Chem. Mater. 16, 544-550 (2004)

32. Y. Zhou, J.H. Schattka, M. Antonietti, Nano Lett. 4, 477-481 (2004)

33. B.G. Trewyn, C.M. Whitman, V.S.-Y. Lin, Nano Lett. 4, 2139$2143(2004)$

34. J.R. Harjani, R.D. Singer, M.T. Garcia, P.J. Scammells, Green Chem. 11, 83-90 (2009)

35. J. Marek, P. Stodulka, J. Cabal, O. Soukup, M. Pohanka, J. Korabecny, K. Musilek, K. Kuca, Molecules 15, 1967-1972 (2010)
36. K. Möller, J. Kobler, T. Bein, Adv. Funct. Mater. 17, 605-612 (2007)

37. W.H. Fu, Y. Guan, Y.M. Wang, M.Y. He, Microporous Mesoporous Mater. 220, 168-174 (2016)

38. M.M. Wan, J.Y. Yang, Y. Qiu, Y. Zhou, C.X. Guan, Q. Hou, W.G. Lin, J.H. Zhu, ACS Appl. Mater. Interfaces 4, 4113-4122 (2012)

39. A.J. Ward, A. a Pujari, L. Costanzo, A.F. Masters, T. Maschmeyer, Nanoscale Res. Lett. 6, 192-200 (2011)

40. K. Zhu, F. Požgan, L. D’Souza, R.M. Richards, Microporous Mesoporous Mater. 91, 40-46 (2006)

41. X. Li, B. Shi, Y. Wang, M. Li, Y. Liu, L. Gao, L. Mao, Microporous Mesoporous Mater. 214, 15-22 (2015)

42. P. Chandrasekaran, G. Viruthagiri, N. Srinivasan, J. Alloys Compd. 540, 89-93 (2012)

43. Y.J. Yu, J.L. Xing, J.L. Pang, S.H. Jiang, K.F. Lam, T.Q. Yang, Q.S. Xue, K. Zhang, P. Wu, ACS Appl. Mater. Interfaces 6, 22655-22665 (2014) 